Volume 5

2019

\title{
Disability, Gender and Race: Does Educational Attainment Reduce Earning Disparity for All or Just Some?
}

\author{
David C. Baldridge \\ Oregon State University \\ Mukta Kulkarni \\ Indian Institute of Management Bangalore \\ Beatrix Eugster \\ St. Gallen University \\ Richard Dirmyer \\ National Technical Institute for the Deaf-NTID
}

Follow this and additional works at: https://scholarworks.bgsu.edu/pad

Part of the Human Resources Management Commons, Industrial and Organizational Psychology

Commons, and the Other Psychology Commons

How does access to this work benefit you? Let us know!

\section{Recommended Citation}

Baldridge, David C.; Kulkarni, Mukta; Eugster, Beatrix; and Dirmyer, Richard (2019) "Disability, Gender and Race: Does Educational Attainment Reduce Earning Disparity for All or Just Some?," Personnel Assessment and Decisions: Number 5 : Iss. 2 , Article 11.

DOI: https://doi.org/10.25035/pad.2019.02.011

Available at: https://scholarworks.bgsu.edu/pad/vol5/iss2/11

This Main Article is brought to you for free and open access by the Journals at ScholarWorks@BGSU. It has been accepted for inclusion in Personnel Assessment and Decisions by an authorized editor of ScholarWorks@BGSU. 


\title{
Disability, Gender And Race: Does Educational Attainment Reduce Earning DisParity for All or Just SOMe?
}

\author{
David C. Baldridge ${ }^{1}$, Mukta Kulkarni ${ }^{2}$, Beatrix Eugster ${ }^{3}$, and \\ Richard Dirmyer ${ }^{4}$
}

\author{
1. Oregon State University \\ 2. Indian Institute of Management Bangalore \\ 3. St. Gallen University \\ 4. National Technical Institute for the Deaf - NTID
}

ABSTRACT

\begin{abstract}
KEYWORDS
disability, education, gender, race, pay equality, discrimination
\end{abstract}

\begin{abstract}
Although interest in research on persons with disabilities has grown steadily, these individuals continue to encounter workplace discrimination and remain marginalized and understudied. We draw on human capital and discrimination theories to propose and test hypotheses on the effects of educational attainment on earnings (in)equality for persons with disabilities and the moderating influence of gender and race using 885,950 records, including 40,438 persons with disabilities from the American Community Survey 2015 (United States Census Bureau, 2015). Consistent with human capital theory, we find that persons with disabilities benefit from greater educational attainment, yet consistent with disability discrimination theories, we find evidence that they are less likely to convert educational gains for master's and higher degrees into earning gains, and consistent with theories on multiple sources of discrimination, we find that women with disabilities may be doubly disadvantaged. These results, however, are mixed and complex. Considering the importance of harnessing diverse talent in organizations, we outline implications for research and practice toward reducing workplace discrimination.
\end{abstract}

Examining workplace outcomes-such as earnings (in)equality - of persons with disabilities (PWD) is important as the number of PWD is expected to grow worldwide given ageing workforces and the association between age and disability (McDaniel \& Zimmer, 2016). Although educational attainment is an important predictor of earnings (Ng, Eby, Sorensen, \& Feldman, 2005), the literature does not give us a concrete answer as to whether or not educational attainment levels the playing field for PWD and, in particular, for women and racial minorities with disabilities (Baldridge, Beatty, Konrad, \& Moore, 2015).

To address this gap in the literature, we draw on human capital theory and discrimination theories to propose and then test hypotheses on the effects of education, disability, gender, and race on earnings (in)equality using 885,950 records, including 40,438 PWD from the American Community Survey 2015 (ACS). Based on human capital theory (Becker, 2009), we expect education to increase earnings, yet based on disability discrimination theories (Colella \& Bruyere, 2011), we expect PWD to benefit less in terms of earning gains. Double discrimination theory further suggests that women and racial minorities with disabilities may be doubly disadvantaged when perceived to be members of multiple groups (Dipboye \& Halverson, 2004; Smith-Randolph \& Andresen, 2004; Stone \& Colella, 1996).

In exploring these relationships empirically, the current study contributes to the literature on workplace disability discrimination in the following ways. First, we emphasize the importance of career success (cf. Baldridge \& Kulkarni, 2017; Kulkarni \& Gopakumar, 2014) over and above pure labor market participation (e.g., Araten-Bergman, 2016). Second, we do so by focusing on objective indicators such as earnings and thus complement research focusing pri-

\footnotetext{
Corresponding author:

David C. Baldridge

Oregon State University, College of Business

2751 SW Jefferson St., Corvallis, OR 97330

Email: david.baldridge@oregonstate.edu
} 
marily on subjective success and individual strategies (e.g., mindsets or disability advocacy, Kulkarni \& Gopakumar, 2014). Finally, the importance of individual differences such as gender, race, and education was stressed in Stone and Colella's (1996) seminal disability framework, yet a recent literature review finds that these attributes remain understudied (Beatty, Baldridge, Boehm, Kulkarni, \& Colella, 2018).

\section{Disability, Discrimination, and Earnings (In)equality}

As noted, human capital theory (Becker, 2009) suggests a positive association between level of educational attainment and earnings. This is expected because human capital includes knowledge, skills, and abilities acquired with higher levels of education, so greater educational attainment should lead to increased human capital, greater economic contribution, and higher earnings (Becker, 2009). This theory about education and earnings however is far too simple. If education only influenced earnings through productivity, then the influence of education on earnings should be equal for PWD and others, assuming that education is equally productivity enhancing for PWD and others. Research on the employment experiences of PWD, however, suggests that PWD still face multiple sources of disadvantage including continuing stigmatization and stereotyping (Beatty et al., 2018). We, therefore, expect that in terms of earnings equality, PWD will benefit less from educational attainment than persons without a disability and that the extent of this inequality will be greater as level of educational attainment increases. Although there are many potential contributing factors (Colella \& Bruyere, 2011), stereotyping theory suggests that organizational members often hold negative stereotypes about PWD such as helplessness, inferiority, and less competitiveness that limit PWD's ability to turn educational gains into earning gains, in particular, for more competitive, higher paying jobs requiring higher levels of education. Similarly, disability stigmatization theory adds that disability can also lead to social stigma that negatively influences cognitive information processing about PWD and scripts applied when interacting with PWD such as "child among adults" (Colella \& Bruyere, 2011), which, in turn, can limit the ability of PWD to convert educational gains into earning gains. Research on disability accommodation, for instance, indicates that PWD in higher-level jobs ask for fewer necessary workplace accommodations for fear of raising questions about their competence, which may negatively impact performance and earnings (Harlan \& Robert, 1998).

Indeed, past large-scale data from the American Community Survey that was matched with the O*Net data on occupational job requirements indicated that productivity limitations do not comprehensively explain lower pay of employees with disabilities and that the possible role of discrimination cannot be ruled out (Kruse, Schur, Rogers, \&
Ameri, 2018). This is likely the case because of attitudinal and structural barriers that manifest themselves in jobs and workplaces designed for persons without disabilities (Lindstrom, Hirano, \& Thomas, 2018). For example, although psychological processes are less readily understood, lack of accommodation, inflexible supervision, and noninclusive climates (Beatty et al., 2018) may limit the ability to turn educational gains into earnings gains. Thus, the earnings gap may actually increase with higher levels of education, and we expect that the negative association between disability and annual earnings is accentuated at higher levels of education (cf. Kruse et al., 2018). Therefore:

Hypothesis 1: (a) In terms of earnings equality, PWD benefit less from educational attainment than persons without a disability and (b) the extent of this inequality is greater as level of educational attainment increases.

\section{Disability, Gender, Race, and Earnings (In)equality}

Theories about treatment of PWD, however, suggests that women and racial minorities with disabilities may face double discrimination (Stone \& Colella, 1996). This is expected because in addition to stigmatization and stereotyping related to disability, women and racial minorities with disabilities may also experience gender and race related stigmatization and stereotyping (Stone \& Colella, 1996; Woodhams, Lupton, \& Cowling, 2015) from multiple stigma statuses (Gibson \& Gibson, 2017; Woodhams et al., 2015). More specifically, prior research indicates that gender-based discrimination may compound disability-related discrimination (Gunderson \& Lee, 2016) given double sources of discrimination (Deegan \& Brooks, 1985). Although there is some evidence that educational attainment may attenuate earnings discrimination effects (Gunderson \& Lee, 2016), the evidence is mixed (Blázquez, Herrarte, \& Llorente-Heras, 2018; Leuze \& Strauß, 2016), necessitating more research. On balance, due to double discrimination faced by many women with disabilities, we expect men with disabilities to have higher earnings and that the gap in earnings between men and women with disabilities will increase at higher levels of education. Formally stated:

Hypothesis 2: Men with disabilities have higher annual earnings than women with disabilities.

Hypothesis 3: (a) In terms of earnings equality, women with disabilities benefit less from educational attainment than men with disabilities and (b) the extent of this inequality is greater as level of educational attainment increases.

Aforesaid arguments also apply to racial minorities with disabilities as they too often face multiple sources of discrimination (cf. McGregor, 2018; Woodhams et al., 2015). 
Less research is available on the compounding effects of disability and race (Kirton \& Greene, 2015), and much of the available research has already been discussed because these studies tend to examine both race and gender. For example, research on disability accommodation also indicates that minorities ask for fewer necessary workplace accommodations, again, for fear of raising questions about their competence (Harlan \& Robert, 1998). Although considerably less research is available, we expect racial minorities with disabilities to experience some degree of double discrimination in part due to race related stigma and stereotyping and, in turn, lower earnings. Formally stated:

Hypothesis 4: Nonminorities with disabilities have higher annual earnings than minorities with disabilities.

Hypothesis 5: (a) In terms of earnings equality, minorities with disabilities benefit less from educational attainment than nonminorities with disabilities and (b) the extent of this inequality is greater as level of educational attainment increases.

\section{METHOD}

\section{Data and Measures}

The ACS is a rotating panel survey administered to approximately 250,000 households each month by the US Census Bureau, resulting in more than three million records annually (United States Census Bureau, 2015). Due to our focus on annual earnings, we pared data down to those in the workforce, with earnings greater than zero, in their prime working years (age 25-54). In total, our sample consists of 885,950 respondents, including 40,438 PWD. Our findings thus generalize to the employed, prime-working age population in the US but not to other population groups such as nonemployed PWD.

\section{Measures and Analysis}

Earnings. ACS respondents are asked about their yearly salary, wages, commissions, bonuses, and tips from all jobs as an aggregate figure. A logarithmic transformation was used to achieve a more normally distributed dependent variable, which also allows interpretation of subsequent coefficients as a percent change in annual earnings.

Disability. The ACS includes six questions about disabling limitations (e.g., "Is this person deaf or does he/she have serious difficulty hearing?"; please see ACS, 2015 for a complete listing). In our analysis, those indicating any disabling condition were coded (1) for $P W D$. Others were coded (0) for persons with no disability.

Educational attainment. ACS respondents are asked to specify the highest level of education completed. In our analysis, education is operationalized into five common degree categories: no degree (baseline category), high school/ equivalent, associate (2 years), bachelor's (4 years), and master's or higher.

Gender. The ACS also asks about sex, which we coded as male (1), female (0).

Minority status. ACS respondents provide their race/ ethnicity. In our analyses, minorities are coded (1), nonminorities (0).

Controls. We control for age, hours, managerial status, and employer type because these variables have been shown to impact earnings ( $\mathrm{Ng}$ et al., 2005).

Analysis. We use OLS regression analyses including two- and three-way interactions to help test our hypotheses. We introduce higher order interactions step by step. All regression analyses are weighted, applying the ACS survey weights. A note of caution is warranted regarding inference. The sheer size of the ACS data allows obtaining statistical significance even for small effect sizes. Therefore, relying on $p$-values alone can result in conclusions with little practical significance. Thus, we interpret effect sizes in addition to statistical significance.

\section{RESULTS}

Tables 1, 2, and 3 show descriptive statistics, correlations and OLS regression analyses. Table 3 shows OLS regression models testing our five hypotheses. Main effect models were first fit and tested for significance prior to investigation of two- and three-way interactions.

Model 1 shows that PWD have expected earnings 29.9\% lower than persons without disabilities. The negative, statistically significant term, representing disability status establishes a foundation for our subsequent hypotheses, which also incorporate educational attainment, gender, and minority status as moderators. Model 2 introduces a set of two-way interactions between disability and each educational attainment level. In comparison to those without a high school degree, people without disability earn $31.3 \%$ more if they earn a high-school degree, $51.6 \%$ more for an associates, $78.8 \%$ more for a bachelor's, and $103 \%$ more for a master's/higher degree. For PWD, the effect of education is taken to be the composite of the main and interaction effects. Interaction effects were not significantly different from zero, except for at the master's/higher level. That is, Hypothesis 1a is only supported at the master's/higher level. Given that a difference was only found at one educational level, there was no basis for testing H1b.

$\mathrm{H} 2$ shifts focus to gender differences and predicts that men with disabilities have higher annual earnings than women with disabilities. Model 3 introduces a higher ordered two-way interaction between gender and disability. This interaction is found to be statistically significant and negative. By comparing the coefficients for women with disabilities $(-0.288)$ to men with disabilities $(0.241-.288$ $0.021=-0.068$ ), we observe a $22.0 \%$ overall earnings gap, 
thus providing support for $\mathrm{H} 2$.

H3a predicts that in terms of earnings equality, women with disabilities benefit less from educational attainment than men with disabilities. To test this hypothesis, Model 4 introduces the three-way interaction between educational attainment, gender, and disability. Statistical significance is only found at the associate degree level. Given that a difference was only found at one educational level, there was no basis for testing $\mathrm{H} 3 \mathrm{~b}$.

In $\mathrm{H} 4$, we shift focus to race, and its effect on earnings, along with consideration for educational attainment and disability status. We hypothesize here that nonminorities with disabilities have higher annual earnings than minorities with disabilities. Model 5 introduces a higher ordered two-way interaction between minority status and disability. This interaction is not found to be statistically significant, providing no support for $\mathrm{H} 4$. Because significance was not found between the two-way interaction involving disability and minority status, there was no basis for testing H5. Additional analyses were conducted, post-hoc, in an attempt to better understand the nonsignificant findings for $\mathrm{H} 4$ and H5. In particular, a regression model fitting only main effects for each primary ethnic/race group finds significant differences in earnings, all else equal. Specifically, Black/
African Americans and Hispanic/Latinos earn less, and Asians more, than Whites.

Post hoc analyses were also conducted to explore the possibility that managerial status and hours worked might mediate the relationship between disability and earnings. Regression analyses indicate significant relationships between disability status and managerial status and between disability status and hours work. Significant relationships between managerial status and earnings, and between hours worked and earnings, were also found, and the effect of disability status on earnings was reduced when these variables are included suggesting partial mediation.

\section{DISCUSSION}

We drew on human capital and discrimination theories to test hypotheses regarding the extent to which educational attainment impacts the negative association between disability and career success in terms of annual earnings. We also examined this association when gender and race of PWD are also considered. Results from our analysis of US government ACS data show that PWD continue to earn less than those with no disability. Consistent with human capital theory, we find that for

TABLE 1.

Descriptive Statistics

\begin{tabular}{lcccccc}
\hline & \multicolumn{2}{c}{ All } & \multicolumn{2}{c}{ Disability } & \multicolumn{2}{c}{ No disability } \\
\hline Variable & Mean & $S D$ & Mean & $S D$ & Mean & $S D$ \\
\hline Ln(earnings) & 10.50 & 0.98 & 10.02 & 1.21 & 10.53 & 0.96 \\
Disability & 0.05 & 0.21 & & & & \\
High school & 0.43 & 0.50 & 0.55 & 0.50 & 0.43 & 0.49 \\
Associate degree & 0.10 & 0.30 & 0.10 & 0.30 & 0.10 & 0.30 \\
Bachelor degree & 0.25 & 0.43 & 0.15 & 0.36 & 0.25 & 0.43 \\
Master degree or higher & 0.15 & 0.35 & 0.08 & 0.27 & 0.15 & 0.36 \\
Male & 0.52 & 0.50 & 0.53 & 0.50 & 0.52 & 0.50 \\
Minority & 0.23 & 0.42 & 0.23 & 0.42 & 0.23 & 0.42 \\
Age & 40.14 & 8.78 & 42.27 & 8.85 & 40.04 & 8.76 \\
Hours worked & 41.06 & 11.21 & 38.05 & 13.70 & 41.20 & 11.05 \\
Manager & 0.12 & 0.32 & 0.08 & 0.27 & 0.12 & 0.32 \\
Nonprofit/government employer & 0.24 & 0.43 & 0.26 & 0.44 & 0.24 & 0.42 \\
Observations & \multicolumn{2}{c}{885,950} & 40,438 & & 845,512 \\
\hline
\end{tabular}

Note. The table presents sample descriptives. No weights included. Source: USCB 2015 public use microdata sample 


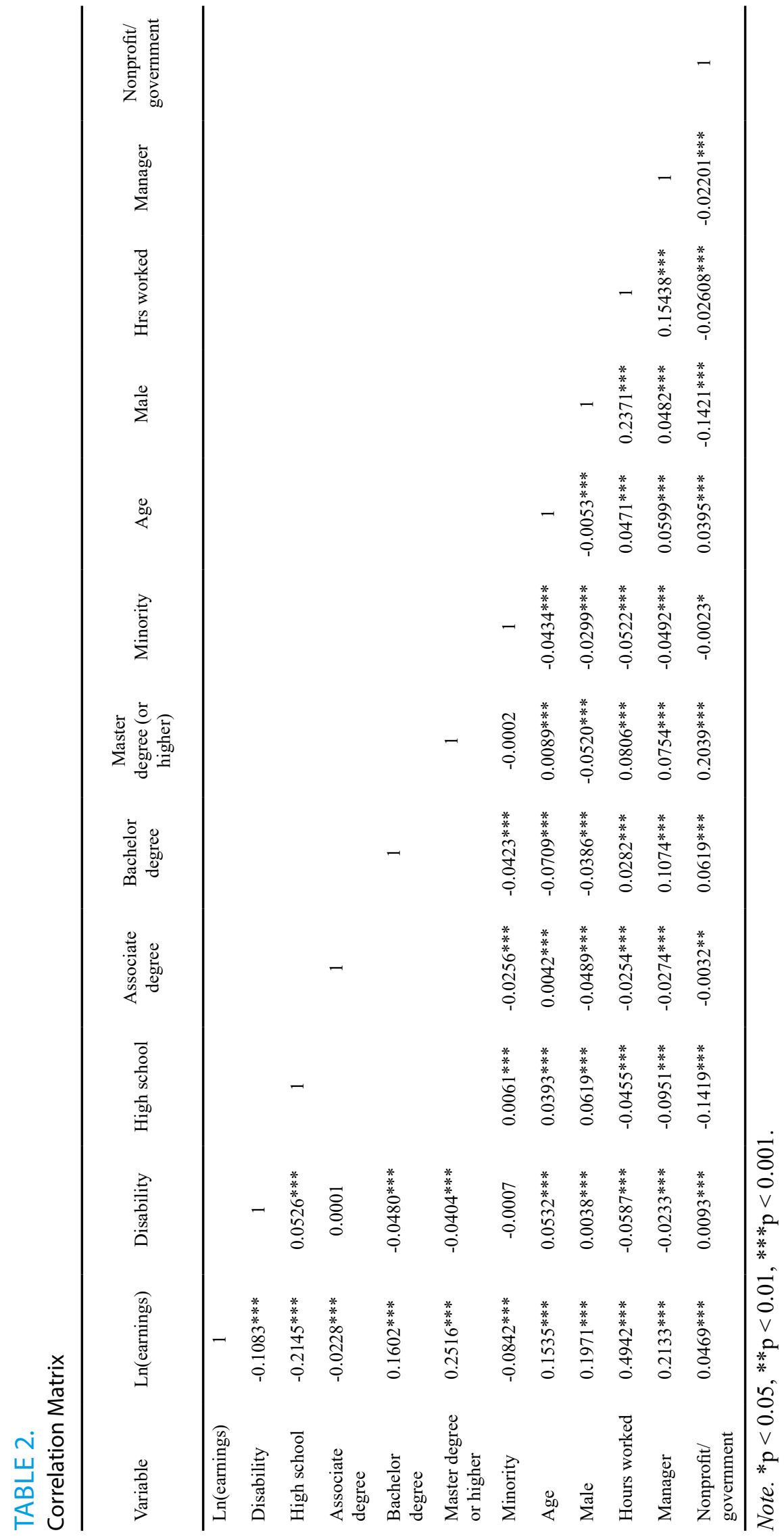


TABLE 3.

\section{OLS Regression Analysis Summary}

\begin{tabular}{|c|c|c|c|c|c|}
\hline Variable & Model 1 & Model 2 & Model 3 & Model 4 & Model 5 \\
\hline Disability & $-0.299 * * *(0.005)$ & $-0.284 * * *(0.013)$ & $-0.288 * * *(0.008)$ & $-0.239 * * *(0.028)$ & $-0.304 * * *(0.005)$ \\
\hline High school degree & $0.312 * * *(0.004)$ & $0.313^{* * *}(0.004)$ & $0.312 * * *(0.004)$ & $0.345^{* * *}(0.007)$ & $0.312 * * *(0.004)$ \\
\hline Associate degree & $0.516^{* * *}(0.005)$ & $0.516^{* * *}(0.005)$ & $0.516^{* * *}(0.005)$ & $0.573 * * *(0.008)$ & $0.516^{* * *}(0.005)$ \\
\hline Bachelor degree & $0.777 * * *(0.005)$ & $0.788^{* * *}(0.004)$ & $0.787 * * *(0.005)$ & $0.819 * * *(0.007)$ & $0.787 * * *(0.005)$ \\
\hline Master degree or higher & $1.030^{* * *}(0.005)$ & $1.032 * * *(0.004)$ & $1.030^{* * *}(0.005)$ & $1.058 * * *(0.007)$ & $1.030 * * *(0.005)$ \\
\hline Gender (male) & $0.240 * * *(0.002)$ & $0.240 * * *(0.002)$ & $0.241 * * *(0.002)$ & $0.289 * * *(0.007)$ & $0.240 * * *(0.002)$ \\
\hline Minority & $-0.072 * * *(0.002)$ & $-0.072 * * *(0.002)$ & $-0.072 * * *(0.003)$ & $-0.072 * * *(0.002)$ & $-0.073^{* * *}(0.003)$ \\
\hline Age & $0.016^{* * *}(0.000)$ & $0.016^{* * *}(0.000)$ & $0.016^{* * *}(0.000)$ & $0.016 * * *(0.000)$ & $0.016^{* * *}(0.000)$ \\
\hline Hours worked per week & $0.036^{* * *}(0.000)$ & $0.036^{* * *}(0.003)$ & $0.036^{* * *}(0.000)$ & $0.036^{* * *}(0.000)$ & $0.036^{* * *}(0.000)$ \\
\hline Manager & $0.272 * * *(0.003)$ & $0.272 * * *(0.003)$ & $0.272 * * *(0.003)$ & $0.272 * * *(0.003)$ & $0.272 * * *(0.003)$ \\
\hline Nonprofit/government employer & $0.011 * * *(0.002)$ & $0.011 * * *(0.002)$ & $0.011^{* * *}(0.003)$ & $0.011 * * *(0.003)$ & $0.011 * * *(0.003)$ \\
\hline DI $\times$ High School Degree & & $-0.017(0.014)$ & & $-0.053(0.030)$ & \\
\hline DI $\times$ Associate Degree & & $0.010(0.021)$ & & $-0.056(0.037)$ & \\
\hline DI $\times$ Bachelor Degree & & $-0.014(0.022)$ & & $-0.048(0.038)$ & \\
\hline DI $\times$ Master Degree/higher & & $-0.052 *(0.023)$ & & $-0.061(0.040)$ & \\
\hline DI $\times$ Gender & & & $-0.021 *(0.011)$ & $-0.071 *(0.037)$ & \\
\hline DI $\times$ Minority & & & & & $0.021(0.014)$ \\
\hline Gender $\times$ High School Degree & & & & $-0.048 * * *(0.008)$ & \\
\hline Gender $\times$ Associate Degree & & & & $-0.106 * * *(0.010)$ & \\
\hline Gender $\times$ Bachelor Degree & & & & $-0.046 * * *(0.008)$ & \\
\hline Gender $\times$ Master Degree/higher & & & & $-0.037 * * *(0.009)$ & \\
\hline DI $\times$ High School Degree $\times$ Gender & & & & $0.054(0.043)$ & \\
\hline DI $\times$ Associate Degree $\times$ Gender & & & & $0.117 *(0.053)$ & \\
\hline DI $\times$ Bachelor Degree $\times$ Gender & & & & $0.048(0.047)$ & \\
\hline DI $\times$ Master Degree/higher $\times$ Gender & & & & $-0.008(0.061)$ & \\
\hline Observations & 885950 & 885950 & 885950 & 885950 & 885950 \\
\hline R-squared & 0.3893 & 0.3893 & 0.3893 & 0.3894 & 0.3893 \\
\hline
\end{tabular}

Note. ${ }^{*} p<0.05, * * p<0.01,{ }^{* *} p<0.001$. Population and replicate weights included. Interactions of interest included, whereas those not considered critical to evaluate hypotheses are excluded from the table but otherwise retained for hierarchy.

persons with and without a disability greater educational attainment is associated with greater annual earnings. Consistent with discrimination theory, however, we find that not everyone benefits equally. In particular, PWD were found to benefit significantly less from educational attainment at the master's and higher level. Consistent with the notion of double discrimination, we find that men with disabilities have higher annual earnings than women with disabilities. Although we did not find evidence that racial minority status acts as a moderator, we did find some evidence that earnings do differ by individual ethnic/race group.

Before discussing limitations and implications for fu- ture research, we briefly discuss how our findings are consistent with, and extend, prior research. First, the finding that those with disabilities, in particular women, experience worse workplace outcomes is consistent with prior research that alludes to double disadvantage from multiple stigma statuses (Gibson \& Gibson, 2017; Woodhams et al., 2015). What we add to this literature is the fact that educational attainment, a perceived equalizer in terms of earnings ( $\mathrm{Ng}$ et al., 2005), does not paint a straightforward story for PWD and, in particular, for women with disabilities. Our findings suggest that although all groups benefit from greater educational attainment, the extent to which educational gains 
result in earnings gains is complex and that greater educational attainment cannot be assumed to level the playing field, especially for high paying jobs requiring advanced degrees. It may be likely that certain groups of employees suffer because they are not completely included and/or are not seen as equally valuable organizational members (Schur, Colella, \& Adya, 2016).

Second, the disability literature indicates that those in higher level jobs and minorities ask for fewer necessary workplace accommodations for fear of raising questions about their competence and may thereby stem their career progress (Harlan \& Robert, 1998). We add to this research by noting that even with educational gains, career progress in the form of earnings remains elusive for these employee groups. In particular, our finding that PWD benefitted significantly less from earning master's or higher level degrees - 5.2\% lower earnings - which are associated with many of the highest paying professional jobs. Present findings lead us to speculate that even with greater educational attainment, PWD may face questions of competence in stakeholders' minds. These findings proffer a more nuanced understanding of earnings differentials and warrant further examination.

Third, as an extension of the points we make above, we agree with Schur, Colella, and Adya (2016) that examining the economic value of managing workplace diversity is a critical factor in today's global and competitive environment. Schur and colleagues (2016) note that impediments to career success (e.g., to pay, job security, and promotion) hinge on institutionalized and attitudinal barriers among employers, supervisors, and coworkers. Present findings lend support to this view by outlining that although educational attainment may indeed overcome some institutionalized biases that work against employees with disabilities (note the increase in earnings based on education), we have a long way to go in terms of complete inclusion (note the uneven increase in earnings across groups). What we see is that barriers to career success noted in prior literature persist after years of legislation and employer attempts towards crafting inclusive and equitable workplaces.

Finally, taken together, these findings contribute to the literature on the workplace experiences of PWD by complementing research focused on success as organizational access (e.g., Lengnick-Hall, Gaunt, \& Kulkarni, 2008) and success as a subjective process driven by individual strategies (e.g., mindsets or disability advocacy, Kulkarni \& Gopakumar, 2014). In doing so, we hope to highlight the different ways in which success of this talent pool can be gauged as well as supported by employers and HR practitioners.

Overall, present findings and focus contribute to the literature by showing that certain groups of employees are less able to convert educational attainment into annual earnings gains, by proffering a more nuanced understanding of earnings differentials, by emphasizing that barriers to inclusion noted in prior literature persist after years of legislation and employer attempts towards crafting inclusive and equitable workplaces. We tie these points together later as we outline implications for HR practice.

\section{Limitations and Suggestions for Future Research}

First, we note that the ACS, although providing a large representative dataset, is cross-sectional so we can observe variables associated with lower earnings but cannot test causality. Moreover, many important variables are not currently available, limiting the ability of researchers to isolate potential drivers of earnings inequity and our ability to identify and reduce sources of workplace discrimination. As noted above, our findings could be driven by people with disabilities receiving less pay for the same jobs or reflect that people with disabilities are disproportionally represented in lower paying jobs. Our findings might also reflect differences in quality or type of education. Thus, the US government needs to collect additional data on PWD attributes and their workplace experiences. For example, structural differences in job types held by PWD, and pay differences for doing the same jobs, need to be understood so that earnings differences can be better explained and addressed. As another example, it is also important to collect additional data on attributes such as age of disability onset and severity. This is important as different disability-specific attributes can elicit different workplace outcomes (Beatty et al., 2018).

Second, it is also important to note that we only examined level of education. Future research is needed that examines differences in the type and quality of education that PWD receive and the associated impact on earnings. In particular, PWD may be self-selecting into degrees such as education, social work, or counseling. Such choices may be based on assumptions about available work options for PWD rather than opting for degrees in business, law, medicine, or engineering that are associated with higher earnings.

Future research should also examine potential differences associated with disability type and the possibility that hours worked and managerial status act as mediators. Finally, we wish to stress that annual earnings are only one indicator of career success and encourage future research on career mobility and satisfaction.

\section{Implications for Human Resource Practice}

Present findings and focus lead to the following implications for HR practice. HR practitioners should attend to the finding that educational attainment-a key proxy for knowledge, skills, and abilities - does not help all organization employee groups equally. The implication of this finding is that HR practitioners need to examine overt as well as subtle attitudinal barriers and discriminatory stances 
toward underrepresented employee groups. Examining the quantum and reasons for differential earnings is important as such job-related factors can affect the satisfaction, performance level, commitment, organizational citizenship behaviors, as well as turnover intention of PWD (Schur et al., 2016; Stone \& Colella, 1996).

In a world where bionics and other technologies allow persons with hearing impairments to "hear" (e.g., cochlear implants), people with visual impairments to "see" (e.g., bionic eyes) and those with locomotor impairments to "walk" (e.g., robotic legs), HR practitioners need to constantly reassess how discriminatory barriers can be reduced as educational attainment takes precedence over how employees look, sound, and move. Educational gains can especially be utilized via flexible and specialized jobs.

HR practitioners can also play a key role in their organizations' inclusion efforts by shaping clear human resource principles and programs in achieving organizational outcomes such as those focused on diversity and inclusivity (Baumgärtner, Dwertmann, Boehm, \& Bruch, 2015). For example, beliefs regarding inclusion of all employees, regardless of diversity facet, can be inculcated through specific programs such as sensitization workshops and processual audits aimed at creating and maintaining equality. Doing so at the organizational level is particularly useful as research shows that when organizational policies and procedures are clear, and there is top leadership commitment towards hiring and post-entry support for PWD, individual manager biases may be reduced (Kulkarni, 2016).

The finding about added disadvantages for certain groups (e.g., that women with disabilities have lower annual earnings than men with disabilities) also offers implications for HR practitioners beyond what we have noted above. In such cases, HR practitioners should be aware of both within-group and between-group barriers for certain groups of employees. We agree with Woodhams and colleagues (2015) that "single-axis" category definitions of groups can conceal disadvantages experienced by employees who belong to multiple categories. Thus, equality diagnostics should be disaggregated to expose finer grained outcomes for those most vulnerable to discrimination.

\section{REFERENCES}

Araten-Bergman, T. (2016). Managers' hiring intentions and the actual hiring of qualified workers with disabilities. International Journal of Human Resource Management, 27(14), 1510-1530.

Baldridge, D., Beatty, J., Konrad, A., \& Moore, M. (2015). People with disabilities: Identity, stigmatization, accommodation, and intersection with gender and aging effects on employment opportunities. In R. Bendl, I. Bleijenbergh, E. Henttonen, and A. J. Mills, (Eds.), The Oxford Handbook of diver- sity in organisations. Oxford UK: Oxford University Press.

Baldridge, D. \& Kulkarni, M. (2017). The shaping of sustainable careers post hearing loss: Toward greater understanding of adult onset disability, disability identity, and career transitions. Human Relations, 70(10), 1217-1236.

Baumgärtner, M. K., Dwertmann, D. J., Boehm, S. A., \& Bruch, H. (2015). Job satisfaction of employees with disabilities: The role of perceived structural flexibility. Human Resource Management, 54(2), 323-343.

Beatty, J., Baldridge, D., Boehm, S., Kulkarni, M., \& Colella, A. (2019). On the treatment of persons with disabilities in organizations: A review and research agenda. Human Resource Management, https://doi.org/10.1002/hrm.21940.

Becker, G. S. (2009). Human capital: A theoretical and empirical analysis, with special reference to education. Chicago, IL: University of Chicago Press.

Blázquez, M., Herrarte, A., \& Llorente-Heras, R. (2018). Competencies, occupational status, and earnings among European university graduates. Economics of Education Review, 62, 16-34.

Colella, A. J. \& Bruyère, S. M. (2011). Disability and employment: New directions for industrial and organizational psychology. In S. Zedeck (Ed.), APA handbook of industrial/organizational psychology, (pp. 473-503). Washington, DC: American Psychological Association.

Deegan, M. J. \& Brooks, N. A. (Eds.) (1985). Women and disability: The double handicap. Piscataway, NJ: Transaction Publishers.

Dipboye, R. L. \& Halverson, S. K. (2004). Subtle (and not so subtle) discrimination in organizations. In Griffin, R., \& O'Leary-Kelly, Anne. (2004). The dark side of organizational behavior (1st ed.).). Organizational Frontiers Series. San Francisco, CA: Jossey-Bass.

Gibson, D. S., \& Gibson, E. P. (2017). Age-earning profiles: Refinement and applications. Rehabilitation Professional, 25(1): 13-34.

Gunderson, M. \& Lee, B. Y. (2016). Pay discrimination against persons with disabilities: Canadian evidence from PALS. International Journal of Human Resource Management, 27(14): 1531-1549, DOI: 10.1080/09585192.2015.1072106.

Harlan, S. L. \& Robert, P. M. (1998). The social construction of disability in organizations: Why employers resist reasonable accommodation. Work and Occupations, 25(4), 397-435.

Kirton, G., \& Greene, A. M. (2015). The dynamics of managing diversity: A critical approach. Abingdon, UK: Routledge.

Kruse, D., Schur, L., Rogers, S., \& Ameri, M. (2018). Why do workers with disabilities earn less? Occupational job requirements and disability discrimination. British Journal of Industrial Relations, 56(4), 798-834.

Kulkarni, M. (2016). Organizational career development initiatives for employees with a disability. International Journal of Human Resource Management, 27(13-14), 1662-1679.

Kulkarni, M., \& Gopakumar, K. V. (2014). Career management strategies of people with disabilities. Human Resource Management 53(3), 445-466.

Lengnick-Hall, M. L., Gaunt, P. M., \& Kulkarni, M. (2008). Overlooked and underutilized: People with disabilities are an untapped human resource. Human Resource Management, 47(2), 255-273. 
Leuze, K., \& Strauß, S. (2016). Why do occupations dominated by women pay less? How "female-typical" work tasks and working-time arrangements affect the gender wage gap among higher education graduates. Work, Employment \& Society, 30(5), 802-820.

Lindstrom, L., Hirano, K., \& Thomas, R. (2018). Career development for individuals with disabilities: Examining issues of equity, access and opportunity. In A. M. Broadbridge, , and S. L. Fielden, (Eds.)., Research handbook on diversity and careers (pp. 161-178). Northampton, MA: Edward Elgar Publishing.

McDaniel, S. A., \& Zimmer, Z. (Eds.). (2016). Global ageing in the twenty-first century: Challenges, opportunities and implications. New York, NY: Routledge.

McGregor, J. (2018). Older women and career development: Double (triple) jeopardy plus or endless opportunities? In A. M. Broadbridge, and S. L. Fielden, (Eds.), Research handbook on diversity and careers (pp. 60-74). Northampton, MA: Edward Elgar Publishing.

Ng, T. W. H., Eby, L. T., Sorensen, K.L., \& Feldman, D.C. (2005). Predictors of objective and subjective career success: A metaanalysis. Personnel Psychology, 58(2), 367-408.

Smith-Randolph, D., \& Andresen, E. (2004). Disability, gender and unemployment relationships in the United States from the behavioral risk surveillance system. Disability \& Society, 19, 403-414.

Schur, L., Colella, A., \& Adya, M. (2016). Introduction to special issue on people with disabilities in the workplace. International Journal of Human Resource Management, 1-6.

Stone, D. L., \& Colella, A. (1996). A model of factors affecting the treatment of disabled individuals in organizations. Academy of Management Review, 21(2), 352-401.

United States Census Bureau. (2015). American Community Survey (ACS). Retrieved from https://www.census.gov/programs-surveys/acs/.

Woodhams, C., Lupton, B., \& Cowling, M. (2015). The snowballing penalty effect: multiple disadvantage and pay. British Journal of Management, 26(1), 63-77.

RECEIVED 03/17/18 ACCEPTED 02/06/19 